\title{
ESPÉCIE NOVA DE Aglaopteryx HEBARD, 1917 (BLATTELLIDAE, PSEUDOPHYLLODROMIINAE) COLETADA EM NINHOS DE VESPAS (HYMENOPTERA, SPHECIDAE) NO ESTADO DO AMAZONAS, BRASIL
}

\section{Sonia Maria Lopes \& Edivar Heeren de Oliveira}

\begin{abstract}
New species of Aglaopteryx Hebard, 1917 (Blattellidae, Pseudophyllodromiinae) collected in wasp nests (Hymenoptera, Sphecidae) from Amazonas State, Brazil - Aglaopteryx sacrificata sp. nov. is described on the basis of the morphological characters of the genitalia of the male, which are illustrated. The species was collected from the nests of solitary wasps of the family Sphecidae (Hymenoptera) from the Amazonas State, Brazil.

Key words: Aglaopteryx sp. nov., Blattaria, Amazonas, taxonomy

\section{Resumo}

Aglaopteryx sacrificata sp. nov. é descrita com base em caracteres morfológicos da genitália do macho. A espécie foi coletada em ninhos de vespas solitárias da família Sphecidae, no estado do Amazonas, Brasil.

Palavras-chave: Aglaopteryx sp. nov., Blattaria, Amazonas, taxonomia

Departamento de Entomologia, Museu Nacional, Universidade Federal do Rio de Janeiro, Quinta da Boa Vista, CEP: 20949-040 São Cristóvão, Rio de Janeiro, Brasil. E-mail: sonialf@acd.ufrj.br

Recebido em 11/10/2004.

Aceito em: 30/03/2005.
\end{abstract}




\section{Introdução}

Hebard (1917) descreveu o gênero enfocando a forma geral arredondada e brilhosa do corpo, com as tégminas não alcançando o ápice do abdome e com nervulação do setor discoidal oblíqua; o fêmur anterior com espinhação do tipo $B$, ou seja, uma série de espinhos anteriores pouco maiores e de tamanhos diversos, e uma fileira extensa de espinhos diminutos com dois espinhos maiores apicais; olhos apresentando larga distância entre eles e superfície dorsal do abdome sem modificação, isto é, não especializada.

Segundo Hebard o gênero Aglaopteryx apresenta similaridade com Maretta Bolívar, 1895, Euthlastoblatta Hebard, 1917, Dendroblatta Rehn, 1916 e com Ceratinoptera Brunner, 1865.

Atualmente, são conhecidas 12 espécies cuja distribuição geográfica está registrada desde o sudeste dos Estados Unidos da América do Norte até o Brasil no Estado do Espírito Santo.

Neste trabalho é assinalada pela primeira vez a presença do gênero no Estado do Amazonas e descrita uma espécie nova, cujos exemplares foram coletados associados a ninhos de vespas da família Sphecidae.

\section{Material e Métodos}

Os espécimes foram coletados em ninhos de vespas solitárias da família Sphecidae, em várias áreas entre 70 a $90 \mathrm{~km}$ ao norte de Manaus (2030'S e 60W) em um ecossistema de floresta tropical úmida de terra firme da Amazônia, as quais encontram-se sob um nível de impacto antrópico distinto (Luizão \& Vasconcelos, 2004) (Fig. 7). Foram enviados ao Setor de Blattaria do Museu Nacional do Rio de Janeiro, com informações sobre o número do ninho, onde foi coletado o material e a quantidade de exemplares em cada ninho. Tais exemplares nos foram enviados separadamente em vidros, mergulhados em álcool $70 \%$, alguns em bom estado e outros bastante danificados, seja pela ação de fungos nos ninhos, ou mesmo por já se encontrarem danificados pelas vespas.

A genitália do espécime macho foi preparada e examinada imersa em glicerina, em lâmina, seguindo a metodologia utilizada por Lopes \& Oliveira (2000). A terminologia adotada para genitália foi baseada em Mckittrick (1964). O material encontra-se depositado na coleção do De- 
partamento de Entomologia do Museu Nacional (MNRJ). O mapa utilizado foi consultado no site do IBGE (2004).

\section{Aglaopterix sacrificata sp. nov.}

(Figs. 1-6)

Coloração geral: Castanho brilhante. Cabeça com vértice levemente mais claro. Antenas com tomentosidade dourada e brilhosa. Pronoto com disco central apresentando áreas castanho-escuras, quase negras e áreas amareladas. Tégminas com manchas escuras, irregulares e longitudinais, setor escapular com faixas oblíquas mais escuras, entre as nervuras. Pernas com a base das coxas, dorso dos fêmures e base da inserção dos espinhos castanho-escuros.

Dimensões (mm): Holótipo macho. Comprimento total: 10,0; comprimento do pronoto: 3,0; largura do pronoto: 3,0; comprimento da tégmina: 8,0 ; largura da tégmina: 3,0 .

Cabeça: Triangular, relativamente grande com vértice exposto. Espaço interocular amplo, medindo cerca de três quartos da área que separa as bases das inserções antenais; antenas longas e filiformes. Pronoto trapezoidal convexo com ápice e base retos e contorno lateral levemente curvo (Fig. 1). Tégminas desenvolvidas atingindo o ápice do abdome. Campo marginal amplo, alongado e bem marcado; campo escapular oblíquo; campo discoidal curto, relativamente amplo e levemente oblíquo; campo anal desenvolvido. Asas com campo anal dobrado em leque e triângulo apical não desenvolvido. Pernas desenvolvidas, fêmures alargados e espinhosos. Fêmur anterior, na face ânteroventral, com três a quatro espinhos pequenos, porém robustos, seguidos por uma série cerrada de pequeninos espinhos em direção ao ápice e dois maiores apicais desenvolvidos; face póstero-ventral com dois espinhos médios, robustos e espaçados e um apical pouco maior que os anteriores. Fêmur médio e posterior nas faces ântero-ventral e póstero-ventral com seis a oito espinhos grandes, robustos e espaçados, sendo um apical. Pulvilos pequenos em todos os artículos das pernas anterior e média e na perna posterior, apenas no quarto artículo. Arólios pequenos, unhas simétricas e simples. 

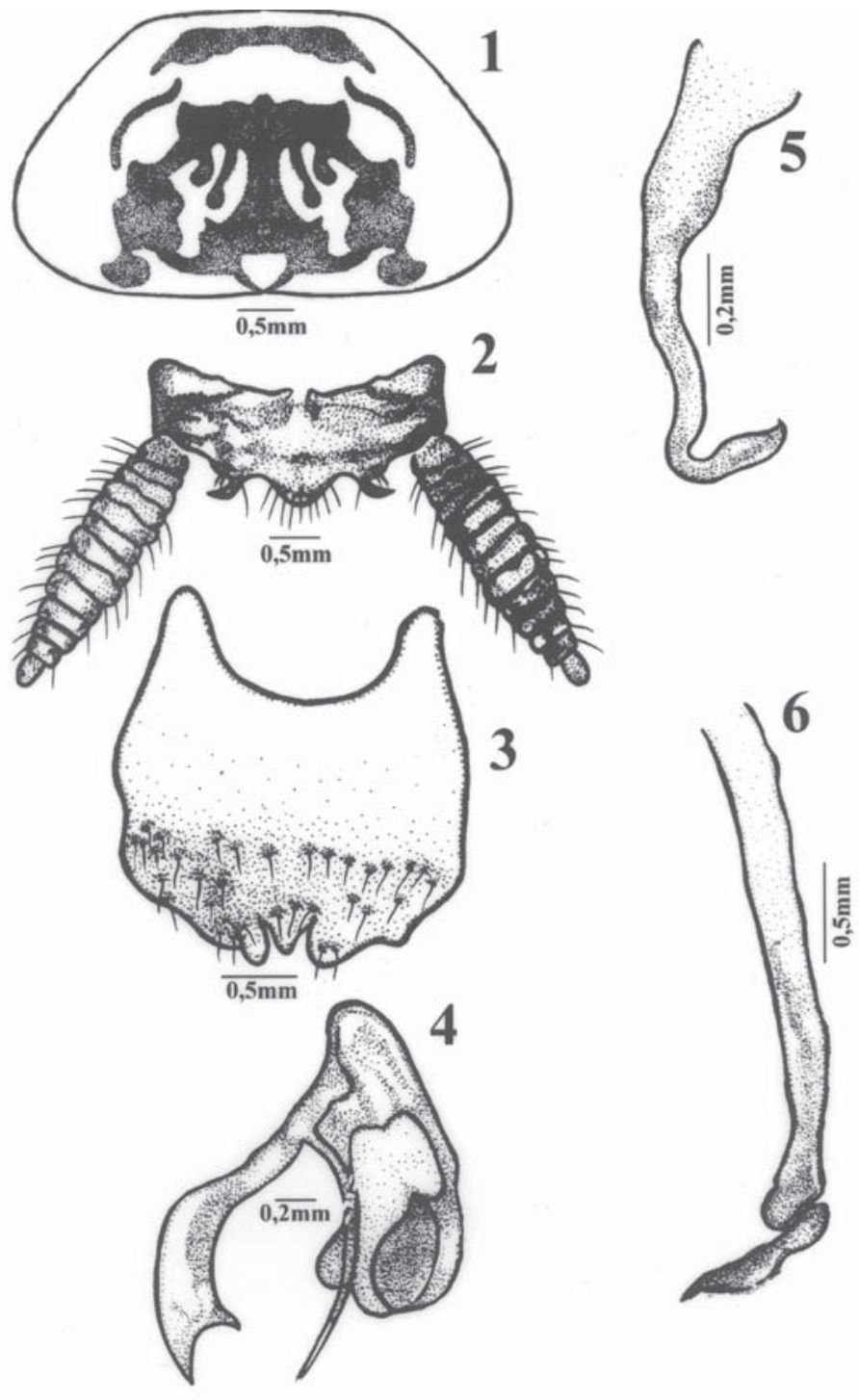

Aglaopteryx sacrificata sp. nov., macho: Fig. 1: pronoto; Fig. 2: placa supraanal; Fig. 3: placa subgenital; Fig. 4: falômero esquerdo (L1); Fig. 5: falômero direito (R2); Fig. 6: esclerito mediano (L2vm). 


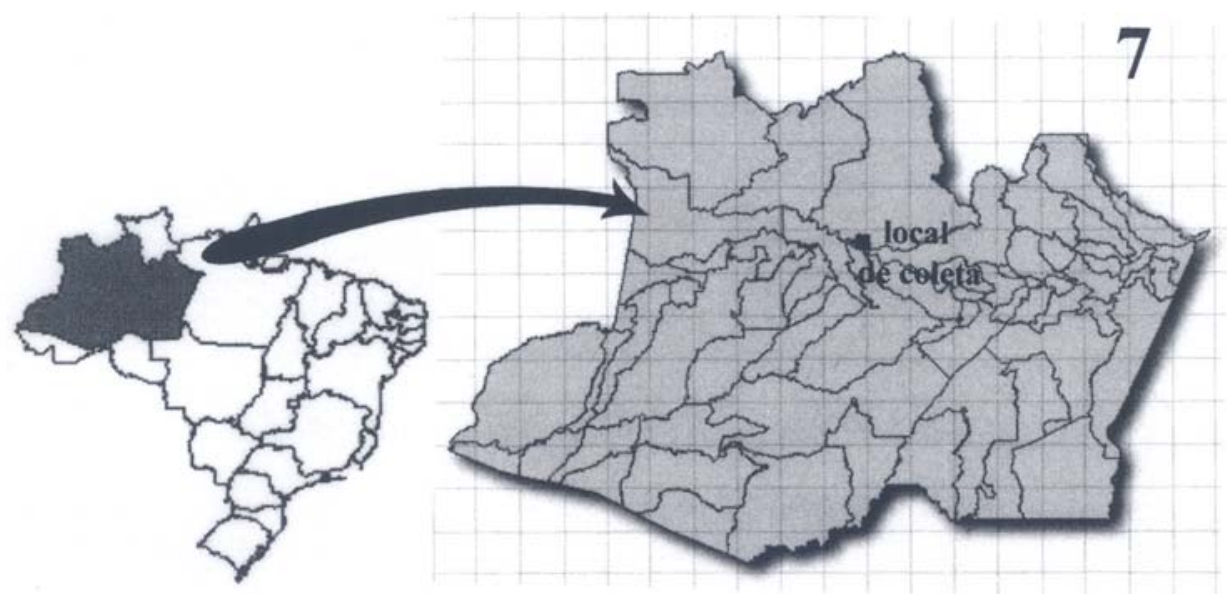

Fig. 7: Mapa da localidade de coleta dos exemplares de Aglaopteryx sacrificata sp. nov. no Estado do Amazonas, Brasil.

Abdome: Placa supra-anal estreitada e ciliada apresentando medianamente proeminência acentuada e projeções afiladas simétricas. Cercos alargados, ciliados e desenvolvidos (Fig. 2). Placa subgenital simétrica, com projeção mediana com estilos arredondados e pequenos pouco se distinguindo da placa (Fig. 3).

Genitália interna: Falômero esquerdo (L1) com um dos braços muito desenvolvido e bifurcado (Fig. 4). Falômero direito (R2) em forma de gancho afilado no ápice (Fig. 5) e esclerito mediano (L2vm) com o ápice (L2d) separado do corpo da estrutura, bastante afilado apicalmente (Fig. 6).

Material examinado: Holótipo macho. BRASIL, Amazonas: 70 a 90 km ao norte de Manaus, 230'S e 60W, coletadas em ninhos de vespas solitárias, 16/08/1989, Elder F. Morato col., ninho 1123/1; parátipo macho, dados iguais ao holótipo, 10/12/1988, ninho 519; parátipo macho, dados iguais ao holótipo 16/08/1989, ninho 1123. 
Etimologia: O nome da espécie é atribuído em relação ao comportamento da vespa que a utiliza como alimento para suas ninfas dentro de seu ninho.

\section{Agradecimentos}

Á Prof ${ }^{a}$ Janira Martins Costa do Depto. de Entomologia do Museu Nacionaldo Rio de Janeiro, pelo apoio técnico. Ao Dr. Elder F. Moratto que atua no Projeto Dinâmica Biológica de Fragmentos Florestais (PDBFF) desenvolvido em Manaus, Amazonas.

\section{Referências Bibliográficas}

Hebard, M., 1917. The Blattidae of North América. Mem. Am. Entomol. Soc. 2:1-284.

IBGE, Instituto Brasileiro de Geografia e Estatística. Disponível em <http://www.ibge.gov.br/cidades> acessado em 07/09/2004.

Mckittrick, F.A., 1964. Evolutionary Studies of Cockroaches. Mem. Cornell Univ. Agric. Exp. St. NY State College of Agric. 389:1-197.

Lopes, S.M. \& Oliveira, E.H., 2000. Espécie nova de Eublaberus Hebard, 1919 do Estado de Goiás, Brasil e notas sobre E. marajoara Rocha e Silva-Albuquerque, 1972 (Blaberidae, Blaberinae). Bol. Mus. Nac.-Zool. 433:1-5.

Luizão, F.J. \& Vasconcelos, H.L., 2004. Floresta Tropical Úmida (Manaus). Disponível em http://www.icb.ufmg.br/ peld/port_site 01.pdf. Consultado em 15/09/2004. 